BMJ Open

Sport \&

Exercise

Medicine

\title{
First overview on chronic injuries in sport climbing: proposal for a change in reporting of injuries in climbing
}

\author{
Gudmund Grønhaug, ${ }^{1}$ Marius Norberg ${ }^{2}$
}

To cite: Grønhaug G, Norberg M. First overview on chronic injuries in sport climbing: proposal for a change in reporting of injuries in climbing. BMJ Open Sport Exerc Med 2016;2:e000083. doi:10.1136/bmjsem-2015000083

- Prepublication history and additional material is available. To view please visit the journal (http://dx.doi.org/ 10.1136/bmjsem-2015000083).

Accepted 1 January 2016

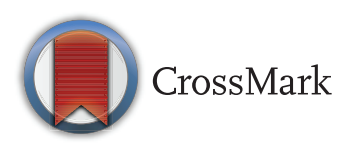

\footnotetext{
${ }^{1}$ Baseline Fysioterapi, Fredrikstad, Norway ${ }^{2}$ Sprek Fysioterapi, Skogn, Norway
}

\section{Correspondence to} Gudmund Grønhaug; NTNU Norwegian University of Science and Technology, Department of Public Health and General Practice, Adres Postboks 8905, MTFS, 7491 Trondheim, Norway; gudmund.gronhaug@ntnu.no

\section{ABSTRACT}

Background: Climbing as a youth sport is growing fast. This is mostly due to indoor walls for training attracting youngsters. With hard training from young ages it is vital to be able to pinpoint training regimes to avoid injuries in athletes. Furthermore, it is vital to know what injuries are most common in the sport to be able to prevent them. Such an overview on injuries does not exist to date. The aim of this overview is to summon the injuries described in published research and to extract the most common.

Method: Two literature searches were conducted in PubMed, on 11 August 2013 and 19 August 2015.

Result: The searches gave 1409 titles. All titles were carefully examined for the possible finding of descriptions of climbing-related chronic injuries. This led to the reading of 96 abstracts and then to a final inclusion of 47 papers of which 17 described chronic climbing-related injuries. We found descriptions of 45 chronic injuries in those 17 papers.

Discussion: Owing to methodological differences, lack of reporting strategies and non-use of control groups in the included papers, it is not possible to conclude on which groups of climbers are more prone to injuries or to state which injuries are the most prevalent among climbers.

\section{BACKGROUND}

Climbing, as a sport, is growing rapidly. The International Federation of Sports Climbing (IFSC) states that currently, worldwide, 25 million people of all ages climb regularly. During the last decade (2001-2012), global numbers of climbers and climbing venues have both increased by approximately $50 \%$. Senior and junior World Championships, a World Cup and a number of international events are held by the IFSC. Parallel to international competitions, many national federations offer national and regional competitions resulting in an activity widespread among youth and adult climbers. ${ }^{1}$

Besides its competitive dimension, sport climbing presents a number of opportunities for climbers at both, professional and leisure levels, to practice the sport in an outdoor

\section{New findings}

- This is the first overview on chronic injuries in climbing.

- It is a proposal for a change in how climbing injuries are reported.

- The study shows that though the reported chronic injuries in climbing are many, few are specific to climbing.

setting. World-class athletes share the outdoor space with recreational climbers in several rock-climbing styles; these are termed lead climbing and bouldering. To measure progress individually, or to compare climbers' achievements, it is also common to report whether a climbing route is taken without previous knowledge of the holds on the route, termed on-sight, or if it is taken after working out the climbing sequences over time, termed red pointing. Climbing routes are graded according to difficulty in various subjective open-ended scales. One of the most used scales is from France, currently ranging from 4 to $9 \mathrm{~b}+$, while there are also scales from the USA, Norway and Australia, to mention a few. Furthermore, there is a climbing intensity score (CIS), and though it has been used in few studies to date, those studies have indicated a correlation between high CIS and high risk of injury. ${ }^{2}$

Concerning chronic injuries, an important discriminating feature between lead climbing and bouldering is the relative intensity of movement. Bouldering consists of shorter paths, so the problems in this type of climbing tend to concentrate all the difficulty of the effort in a few actions. An important similarity between sport climbing and bouldering is their repetitive movements. The tendency to spend longer time 'planning' a route or boulder ${ }^{3}$ might possibly be a leading factor for chronic injury.

To prevent chronic injuries among climbers, knowledge on which injuries to prevent 
is essential. This paper is, as far as we know, the first to collect all chronic injuries related to climbing, and to look into strategies for reporting who gets injured when.

\section{METHOD}

Two semistructured literature searches were conducted (11 August 2013 and 19 August 2015). The searches included six different terms of 'climbing injuries' and 'chronic injuries in climbing' in PubMed. The initial search included all languages. All papers with a hint in the title and/or abstract of possible findings of described chronic injuries in climbing were read in full text. No discrimination regarding documentation on how the included papers had conducted their investigation was made. All chronic injuries, information on research methods and subjects described in included papers, were summoned.

\section{RESULT}

Of the 1409 titles that came up during the search, 96 abstracts were read, leading to inclusion of 47 articles. We found distinct descriptions of chronic injuries related to climbing in 17 of the articles included in the original selection (see online supplementary table).

After grouping the described injuries and removing repeated injury types described in multiple papers, the list of injuries was composed of 45 chronic injuries: 9 in the fingers, 7 in the hand and wrist, 4 in the forearm, 8 in the upper arm or shoulder, 3 in the knees, 1 in the hip, 2 in the back, 1 in the neck, and 9 in the ankle and foot. Several of the injuries were referred to as nonspecific pain.

The methods used to identify chronic injuries in the included papers varied in all aspects (table 1).

One of the papers specifically aimed at elite climbers whereas all included participants were taking part in a national competition. ${ }^{5}$ Of the two reviews, only one described the method used. ${ }^{6}$ In two of the included papers, a differentiation was made in terms of how often an injury appeared due to the level of difficulty climbed. ${ }^{78}$ One of the included papers used a control group to rule out injuries common among the normal non-climbing population. ${ }^{8}$ Participants reported in the included papers ranged from 13 to 93 years of age, and two of the studies had not mentioned the age of included participants. ${ }^{5}{ }^{9}$ Climbing abilities ranged from British moderate (French sport grade one) to French $8 \mathrm{~b}+$. Of the included papers, two described the athletes by years climbed, ${ }^{710}$ five papers used climbing grades, ${ }^{8}{ }^{11-14}$ one of the papers had an inclusion criterion of ' 3 years or more climbing at least French $7 \mathrm{c}$ in a row ${ }^{15}$ and one included numbers but did not connect them to a known scale. ${ }^{16}$ In two of the papers included, ${ }^{3}{ }^{17}$ neither years climbed nor grades were mentioned. Both these papers were case reports and the climbers were described as 'high level' or 'experienced.'

\section{DISCUSSION}

The research on chronic injuries in climbing is relatively new and availability of studies was still limited during this study. The methodology varied in terms of how to define and identify injuries. Methods described in the papers differed, from self-assessed questionnaires to clinical examination (table 1).

The level of climbing was not always mentioned and sometimes reported as years climbed instead of level of difficulty. Two of the papers included ${ }^{15} 16$ made distinctions between different levels of performance among the climbers included. Two of the papers included ${ }^{3} 17$ reported the climbers' abilities either as 'high level' or 'experienced'. One paper ${ }^{18}$ based their reporting of the climbers' abilities using the CIS proposed by Logan et $a l^{4}$ CIS might be the best tool available to make distinctions of a climber's achievement and abilities, but it lacks the discrimination between intermediate and elite achievements, and does not compare the achievements made in bouldering within the sport climbing context, either.

An international consensus based on either the CIS proposal of Logan et $a l^{11}$ or on what levels of grade climbed in a certain style, was regarded as different levels of performance-easy, moderate, high and elite (table 2).

Pieber et $a l^{18}$ made a comparison of different ages among the respondents and reported that younger climbers seem to be more prone to injury than older climbers, disregarding site of injury and how the injury occurred. On the contrary, Jones et $a l^{7}$ reported that older and more skilled climbers are more prone to overuse injuries. This means age was an important factor, along with skill level. Whether the young climbers had acute injuries or not was not known, and it is not known how skilled the climbers were, other than simply being 'skilled'. This emphasises the need for stronger methodologies in terms of climbing grade.

In some of the included studies, no information is available on methods used. In addition, one of the previous reviews ${ }^{9}$ had no information on methodology regarding inclusion criteria of injuries or prevalence regarding described injuries. Although the paper is labelled 'review', it is debatable if it is more than an expert's opinion, due to the non-reporting of inclusion criteria and unmentioned methods for identifying injuries and rates of prevalence. Förster et $a l^{15}$ reported that 'climber's back' is a diagnosis with increasing prevalence due to increasingly complicated climbing techniques, using a control group of recreational climbers.

Owing to methodology, it was questionable whether all of the described injuries were climbing-related injuries. As an example, low back pain (LBP) was included as a diagnosis in two of the included studies, although the studies gave two different conclusions. Schweizer ${ }^{9}$ regarded LBP as a climbing-specific injury, whereas Pieber et $a l^{18}$ reported trunk pain, including LBP, to be prevalent in $5.3 \%$ of the climbers, which was 
Table 1 View of the methods used in the included papers

\begin{tabular}{llllll}
\hline Method & Review & Questionnaire & Observational & Literature search & Clinical examination \\
\hline Number of studies & 2 & 6 & 7 & 1 & 2 \\
\hline
\end{tabular}

considerably less frequent than in the non-climbing population. ${ }^{19}$ Several of the surveys used questionnaires depending on the respondents' memory and perception on what was a reportable injury.

The differences on reported LBP and the findings of Förster et $a l^{15}$ show the importance of not relying on selfreported questionnaires only, and stresses the importance of differentiating between injuries related to climbing and injuries prevalent among climbers.

The participants in the included papers ranged from 13 to 93 years of age. Injury patterns in physical activity and sports differ due to age and abilities. ${ }^{2}$ Still, none of the included papers reported participants in different categories of age, nor did they divide participants into groups based on abilities.

Since the population in the papers differed in all aspects of age and abilities, it was not surprising that the reported injuries also differed in prevalence and occurrence. Pieber et $a l^{18}$ made a comparison of different ages among the respondents and reported that younger climbers seemed to be more prone to injury than older climbers, regardless of injury site and how the injury occurred. Roseborrough and Lebec ${ }^{7}$ found, using a nonclimbing control group, that the position of the scapula differs between climbers and non-climbers. While Förster et $a l^{15}$ reported 'climber's back' as a diagnosis with increasing prevalence due to increasingly complicated climbing techniques, using a control group of recreational climbers.

When information on the style of climbing reported, bouldering or lead climbing, was missing, or when the time span of the performance reported was missing, it was difficult to compare results from different studies. Time of practice alone did not include any reference to intensity or density of climbing performed by the athlete. Even a distinction of style combined with years climbed did not give any relevant data to compare different studies. Differing of populations in the papers may, to some extent, explain the differences in reported prevalence of injuries.

In the included papers, the most prevalent chronic injuries were nail injuries, ${ }^{16}$ collateral ligament injuries in the fingers and non-specific finger pain. ${ }^{8} 1011$ Other non-specific injuries also were among the top prevalent chronic injuries ${ }^{10}$ (table 3 ).

Although many papers differed in respect to how injuries were detected, there was a consensual agreement between several studies regarding both non-specific finger pain $^{11} 1014$ and epicondylitis in the elbow. ${ }^{518}$ This opens the case for more specific climbing preventive measures. On the contrary, considering that several of the most prevalent injuries were a non-specific diagnosis, there should be more focus on assessment in future studies.

Reporting studies with a higher degree of subgroup dividing would make it more complicated to ensure enough respondents to give a correct picture on the pattern of injuries in climbing. However, not reporting with subgrouped data would make it very difficult to interconnect and compare data from various sources and papers. Such comparing of results would, over time, give a clearer picture of what would be relevant diagnosis and pattern of injury among climbers of various abilities and ages.

There is a need for consistent reporting on participants' abilities in future studies, as suggested in this paper. It is possible to convert the grades and style of preferred style of climbing by using our proposed table (table 2). This way of grouping participants will make it easier to compare results from different populations, even if the preferred climbing styles differ.
Table 2 Proposal of corresponding levels of experience between sport climbing and bouldering

\begin{tabular}{lll}
\hline Level of & $\begin{array}{l}\text { Sport climbing, } \\
\text { average red } \\
\text { point level, } \\
\text { experience }\end{array}$ & $\begin{array}{l}\text { French grades } \\
\text { Bouldering, average } \\
\text { level, Fontainebleau } \\
\text { grades }\end{array}$ \\
\hline Recreational & 4 to $6 \mathrm{~b}$ & 4 to $5+$ \\
Intermediate & $6 \mathrm{~b}+$ to $7 \mathrm{a}+$ & $6 \mathrm{~A}$ to $6 \mathrm{C}+$ \\
Experienced & $7 \mathrm{~b}$ to $8 \mathrm{~b}$ & $7 \mathrm{~A}$ to $7 \mathrm{C}$ \\
Elite & $8 \mathrm{~b}$ to $-8 \mathrm{c}+$ & $7 \mathrm{C}+$ to $8 \mathrm{~A}+$ \\
International & $>9 \mathrm{a}$ & $>8 \mathrm{~B}$ \\
Elite & & \\
\hline
\end{tabular}

Table 3 Five most prevalent injuries

\begin{tabular}{|c|c|c|}
\hline Diagnosis & $\begin{array}{l}\text { Per cent } \\
\text { prevalence }\end{array}$ & $\begin{array}{l}\text { Source } \\
\text { (sample size) }\end{array}$ \\
\hline Nail injuries in the foot & 65.3 & Buda $(n=144)$ \\
\hline $\begin{array}{l}\text { Collateral ligament } \\
\text { injuries in the fingers }\end{array}$ & 40.5 & $\begin{array}{l}\text { Rohrbough } \\
(n=42)\end{array}$ \\
\hline $\begin{array}{l}\text { Non-specific finger } \\
\text { pain }\end{array}$ & 35 & $\begin{array}{l}\text { Jones G } \\
(n=201)\end{array}$ \\
\hline $\begin{array}{l}\text { Non-specific shoulder } \\
\text { pain }\end{array}$ & 33.3 & $\begin{array}{l}\text { Rohrbough } \\
(n=42)\end{array}$ \\
\hline $\begin{array}{l}\text { Injuries in 'other } \\
\text { ligaments' in the } \\
\text { fingers }\end{array}$ & 30.7 & $\begin{array}{l}\text { Pieber K } \\
(n=193)\end{array}$ \\
\hline
\end{tabular}




\section{CONCLUSION}

Owing to lack of consistency on reporting the participants' abilities and the wide difference of methods used in the included papers, it is not possible to conclude which injury is the most prevalent chronic climbing-related injury. Although other sports report that injuries are more prevalent in younger and elite athletes, we are not able to conclude on this matter when it comes to climbing, due to lack of consistency on how the injuries are reported in the included papers.

There seems to be a potential for further development in reporting incidence and prevalence of nonacute climbing injuries. This review reveals considerable inconsistencies in the current literature regarding methodological approaches, on reporting strategies, presentation of demographic data and divisions of climbers according to experience, level of skill and frequency of practice. These methodological inconsistencies and lack of accurate stratification of subgroups in climbing populations pose great difficulty when it comes to collecting data. Thus, these disparities render a somewhat large body of evidence that is difficult to scrutinise.

Contributors GG planned the study and wrote the first draft. MN drew the tables and co-authored the paper.

Competing interests None declared.

Provenance and peer review Not commissioned; internally peer reviewed.

Open Access This is an Open Access article distributed in accordance with the Creative Commons Attribution Non Commercial (CC BY-NC 4.0) license, which permits others to distribute, remix, adapt, build upon this work noncommercially, and license their derivative works on different terms, provided the original work is properly cited and the use is non-commercial. See: http:// creativecommons.org/licenses/by-nc/4.0/

\section{REFERENCES}

1. IFSC Homepage. http://www.ifsc-climbing.org/. 28 October 2015.
2. Woollings $\mathrm{KY}$, McKay $\mathrm{CD}$, Emery $\mathrm{CA}$. Risk factors for injury in sport climbing and bouldering: a systematic review of the literature. $\mathrm{Br} J$ Sports Med 2015;49:1094-9.

3. Bayer T, Schweizer A. Stress fracture of the hook of the hamate as a result of intensive climbing. J Hand Surg Eur 2009;34:276.

4. Schweizer A. Lumbrical tears in rock climbers. $J$ Hand Surg 2003;28:187-9.

5. Rohrbough JT, Mudge MK, Schilling RC. Overuse injuries in the elite rock climber. Med Sci Sports Exerc 2000;32:1369-72.

6. El Sheik Y, Wong I, Farrokhayar F, et al. Diagonsis of finger flexor pulley injury in rock climbers: a systematic review. Can J Plast Surg 2008:14:227-31.

7. Roseborrough A, Lebec M. Differences in static scapular position between rock climbers and a non-rock climber population. $N A m ~ J$ Sports Phys Ther 2007:2:44-50.

8. Logan AJ, Makwana N, Mason G, et al. Can rock climbing lead to Dupuytren's disease? Br J Sports Med 2005;39:639-44.

9. Schweizer A. Sport climbing from a medical point of view. Swiss Med Wkly 2012;142:w13688.

10. Jones G, Asghar A, Llewellyn DJ. The epidemiology of rock climbing injuries. Br J Sports Med 2008;42:773-8.

11. Logan AJ, Makwana N, Mason G, et al. Acute hand and wrist injuries in experienced rock climbers. Br J Sports Med 2004;38:545-8

12. Hochholzer T, Schøffl VR. Epiphyseal fractures of the finger middle joints in young sport climbers. Wilderness Environ Med 2005;16:139-42.

13. Schøffl V, Hochholzer T, Schöffl I. Extensor hood syndromeosteophytic irritation of digital extensor tendons in rock climbers. Wilderness Environ Med 2010;21:253-356.

14. Wright DM, Royle TJ, Marshall T. Indoor rock climbing: who gets injured? Br J Sports Med 2001;35:181-5.

15. Förster R, Penka G, Bösl T, et al. Climbers back-form and mobility of the thoracolumbar spine leading to postural adaptations in male high ability rock climbers. Int $J$ Sports Med 2009;30:53-9.

16. Buda R, Di Caprio F, Bedetti L, et al. Foot overuse diseases in rock climbing - an epidemiologic study. J Am Podiatr Med Assoc 2013;103:113-20.

17. Thompson RN, Hanratty B, Corry IS. "Heel hook" rock-climbing manoeuvre: a specific pattern of knee injury. Clin J Sports Med 2011:21:365-8.

18. Pieber K, Angelmaier L, Csapo R, et al. Acute injuries and overuse syndromes in sport climbing and bouldering in Austria: a descriptive epidemiological study. Wien Klin Wochenschr 2012;124:357-62.

19. Ihlebaek C, Hansson TH, Laerum E, et al. Prevalence of low back pain and sickness absence: a "borderline" study in Norway and Sweden. Scand J Public Health 2006; 34:555-8. 


\section{Correction}

Grønhaug G, Norberg M. First overview on chronic injuries in sport climbing: proposal for a change in reporting of injuries in climbing (BMJ Open Sport Exerc Med 2016;2:e000083). The first author's affiliation should be NTNU Norwegian University of Science and Technology and not Baseline Fysioterapi. In Table 2, in the 'Elite' route climbing row there is a ' + ' symbol missing after ' $8 \mathrm{~b}$ '. In addition, we omitted to include the proper attribution for table 2. It is as follows: 'Reproduced from Gudmund Grønhaug. Belastningsskader i klatring page 53. Fabkokforlaget Vigmostad \& Bjørke. Bergen Norway ISBN: 978-82-450-1672-7.' We would like to apologise to the authors for these omissions.

BMJ Open Sport Exerc Med 2016;0:e000083corr1. doi:10.1136/bmjsem-2015-000083corr1

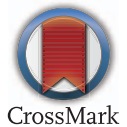

